\title{
BMJ Open Compliance with national guidelines for antibiotic prophylaxis in hip fracture patients: a quality assessment study of 13329 patients in the Norwegian Hip Fracture Register
}

To cite: Lian T, Dybvik E, Gjertsen J-E, et al. Compliance with national guidelines for antibiotic prophylaxis in hip fracture patients: a quality assessment study of 13329 patients in the Norwegian Hip Fracture Register. BMJ Open 2020;10:e035598. doi:10.1136/ bmjopen-2019-035598

- Prepublication history for this paper is available online. To view these files, please visit the journal online (http://dx.doi. org/10.1136/bmjopen-2019035598).

Received 08 November 2019 Revised 26 March 2020 Accepted 21 April 2020

Check for updates

(c) Author(s) (or their employer(s)) 2020. Re-use permitted under CC BY-NC. No commercial re-use. See rights and permissions. Published by BMJ.

For numbered affiliations see end of article.

Correspondence to

Dr Tom Lian;

tom.t.lian@gmail.com

\section{ABSTRACT}

Objective We assessed compliance with new guidelines for prophylactic antibiotics in hip fracture surgery in Norway introduced in 2013.

Design The data from the Norwegian Hip Fracture Register was used to assess the proportion of antibiotics given according to the national guidelines.

Setting All hospitals in Norway performing hip fracture surgery in the period from 2011 to 2016.

Participants We studied 13329 hemiarthroplasties (HAs) for acute hip fracture.

Main outcome measure Type and timing between first and last dose of prophylactic antibiotics compared with the national guidelines.

Results Before the guidelines were introduced, the recommended drugs cephalotin or clindamycin was used in only $86.2 \%$ of all HAs. In 2016 , one of the two recommended drugs was administered in $99.2 \%$ of HAs. However, hospitals' adaption of the recommended administration of the two drugs improved slowly, and by the end of the study period, only three out of five HAs were performed with the correct drug administered in the correct manner. We found major differences in compliance between hospitals.

Conclusions The change towards correct administration of antibiotic prophylaxis was varied both when investigating university and non-university hospitals. We suggest that both hospital leaders and the national Directorate of Health need to investigate routines for better dissemination of information and education to involved parties. Strong leadership concerning evidencebased guidelines on antibiotic prophylaxis in surgery may take away some autonomy from executing healthcare professionals, but will result in better patient care and antibiotic stewardship.

\section{INTRODUCTION}

Due to the complexity of modern medicine, guidelines and checklists have become a necessary part of treatment in all medical fields. For guidelines and checklists to have effect, it is imperative that they are used and
Strengths and limitations of this study

$\Rightarrow$ The strengths of our study are the high coverage and completeness of the Norwegian Hip Fracture Register combined with the large number of patient forms we were able to investigate.

$\Rightarrow$ Another strength is that the forms are filled out by the surgeon immediately after surgery, thereby ensuring correct information regarding prophylaxis.

$\Rightarrow$ One limitation of our study is the lack of clear guidelines for clindamycin as a prophylactic drug.

$\Rightarrow$ There may be a discrepancy between what was filled in on the form and the actual timing of the prophylaxis.

$\Rightarrow$ The last clear limitation is the high number of excluded cases.

followed. Until 2013, there were no national guidelines for prophylactic antibiotics in orthopaedic surgery in Norway, and many different regimens were used. Engesaeter $e t$ $a l^{l}$ found the lowest risk of revision, for any reason, if four doses of antibiotics were administered systemically on the day of surgery in total hip arthroplasty. Extended prophylaxis of 2 or 3 days did not decrease the revision risk compared with four doses administered on the day of surgery according to that study.

Guidelines for prophylactic antibiotics in orthopaedic surgery was first introduced in Norway in 2013. ${ }^{2}$ The guidelines were based on a thorough evaluation of available knowledge, using the Grades of Recommendation Assessment, Development and Evaluation (GRADE) system $^{3}$ as a tool for giving the best possible recommendations and were published on the Norwegian Directorate of Health's website. ${ }^{2}$ The guidelines state that cephalotin, a first-generation cephalosporin, should be the only drug of choice, except in 
cases of penicillin allergy, where clindamycin should be used instead.

Cephalotin has a half-life of about $45 \mathrm{~min}$, and should, therefore, be administered at short intervals (the guidelines state an interval of $90 \mathrm{~min}$ ), to exceed minimal inhibitory concentrations (MIC). It is also recommended that the first dose should be administered 30-60 min before the incision is made. ${ }^{4-7}$ Studies have shown that this first dose probably is the most important one ${ }^{68}$ For arthroplasty procedures, four doses were recommended. In cases of known penicillin allergy, four doses of clindamycin, administered every 6 hours, were recommended. When the guidelines were published, the aim was to improve administration of prophylactic antibiotics. From many different administration regimens, to a uniform regimen throughout Norway.

The aim of this study was to assess whether hospitals in Norway follow the new guidelines published by the Norwegian Directorate of Health, and if so, at what pace the guidelines were implemented.

\section{MATERIAL AND METHODS}

The Norwegian Hip Fracture Register (NHFR) has collected data on all hip fracture procedures in Norway since $2005 .{ }^{9}$ The information about the patient, fracture and type of surgery, as well as type of antibiotic prophylaxis, number of doses and duration recorded as the time interval between the first and the last dose in hours is reported to the NHFR on a one-page questionnaire completed by the surgeon immediately after each surgery. The questionnaires are sent from each hospital to the NHFR database for registration. Both primary surgery and reoperations are registered. The completeness of reporting to the NHFR compared with the Norwegian Patient Registry has been found to be $94.5 \%$ for primary hemiarthroplasties (HAs). ${ }^{10}$

The data from 19106 HAs due to femoral neck fracture registered in the NHFR from 1 January 2011 to 31 December 2016 were evaluated, spanning 2 years before and 4 years after publication of the new guidelines. In this studied period, around $90 \%$ of femoral neck fracture patients in Norway were treated with HA. ${ }^{10}$ Of these, some HAs had incomplete information on the total number of antibiotic doses (2521), type of antibiotic drug (107) and duration of prophylaxis (2805), and were excluded. We also excluded HAs where patients received more than one drug for prophylaxis (344). This left 13329 HAs eligible for analyses.

One large hospital had a high number of excluded patients $(\mathrm{n}=1128)$. From that specific hospital, only 323 cases had been correctly reported, representing an inclusion rate of only $22 \%$. Therefore, this hospital was excluded from the analyses due to infrequent correct reporting. Excluding the remaining reported cases from that hospital did not change our findings. In comparison, 27 hospitals had an inclusion rate of more than $75 \%$ and only 9 had an inclusion rate of between $50 \%$ and $60 \%$.

Analyses of number of doses and duration of cephalotin prophylaxis revealed four main groups: completion of four doses within 4.5, 6, 12 and 24 hours, respectively. The timing of the first dose is not recorded in the NHFR, meaning that verification of whether this dose was given before surgery or not was not possible. We could, however, verify that doses were given at intervals short enough to keep concentrations above MIC. Stipulating that both 4.5 and 6 hours could be interpreted as correct administration of four doses with intervals of $90 \mathrm{~min}$, we decided to treat these as one group, leaving three groups for analyses: in the first group, completion of all doses was registered as administered during the first 6 hours postoperatively; in the second group, it was completed between 7 and 12 hours postoperatively and in the third group, between 13 and 24 hours postoperatively. Four doses of cephalotin administered during the first 6 hours postoperatively were defined as the correct administration according to the guidelines.

The first version of the guidelines did not contain recommendations on number of doses or dosage for clindamycin. Therefore, both three and four doses of

Table 1 Type of antibiotic prophylaxis used from 2011 to 2016

\begin{tabular}{|c|c|c|c|c|c|c|}
\hline & 2011 & 2012 & 2013 & 2014 & 2015 & 2016 \\
\hline Cephalotin total & $1860(82.6 \%)$ & $1926(90.0 \%)$ & $1919(93.1 \%)$ & $2070(95.0 \%)$ & $2109(95.2 \%)$ & $2346(94.8 \%)$ \\
\hline Correct administration (\%) & & & $86(4.5 \%)$ & $406(19.6 \%)$ & 955 (45.3\%) & $1379(58.8 \%)$ \\
\hline Clindamycin total & $82(3.6 \%)$ & $73(3.4 \%)$ & $86(4.2 \%)$ & $86(3.9 \%)$ & $97(4.4 \%)$ & $112(4.5 \%)$ \\
\hline Correct administration (\%) & & & $74(86 \%)$ & $72(83.7 \%)$ & $83(85.6 \%)$ & $100(89.3 \%)$ \\
\hline Other drug & $311(13.8 \%)$ & $142(6.6 \%)$ & $57(2.7 \%)$ & $24(1.1 \%)$ & $9(0.4 \%)$ & $16(0.6 \%)$ \\
\hline Total & 2253 & 2141 & 2062 & 2180 & 2215 & 2474 \\
\hline Correct administration (\%) & & & $7.8 \%$ & $21.9 \%$ & $46.9 \%$ & $59.8 \%$ \\
\hline
\end{tabular}


Table 2 Patient characteristics

\begin{tabular}{|c|c|c|c|}
\hline & $\begin{array}{l}\text { Correct antibiotic and } \\
\text { administration as stated in } \\
\text { the guidelines of } 2013\end{array}$ & $\begin{array}{l}\text { Incorrect antibiotic or } \\
\text { administration as stated in } \\
\text { the guidelines of } 2013\end{array}$ & All groups \\
\hline Age, mean & 82.9 & 82.5 & 82.6 \\
\hline Gender, male (\%) & $1010(30.5)$ & $3020(30.2)$ & $4030(30.2)$ \\
\hline Dementia, uncertain (\%) & $306(9.2)$ & $908(9.1)$ & $1214(9.1)$ \\
\hline Dementia, missing (\%) & $62(1.9)$ & $189(1.9)$ & 251 (1.9) \\
\hline ASA 1 (\%) & $29(0.9)$ & $122(1.2)$ & $151(1.1)$ \\
\hline ASA 2 (\%) & $997(30.1)$ & 3258 (32.5) & $4255(31.9)$ \\
\hline Missing ASA (\%) & $29(0.9)$ & $91(0.9)$ & $120(120)$ \\
\hline Anterolateral approach (\%) & $183(5.5)$ & $741(7.4)$ & $924(6.9)$ \\
\hline Direct lateral approach (\%) & $2466(74.4)$ & $8271(82.6)$ & $10737(80.6)$ \\
\hline Posterior approach (\%) & $634(19.1)$ & $811(8.1)$ & $1445(10.6)$ \\
\hline Other/missing approach (\%) & $33(1)$ & $190(1.9)$ & $223(1.7)$ \\
\hline
\end{tabular}

clindamycin given over a period of 8-24 hours were defined as the correct administration according to the guidelines.

Treatments for all types of hip fractures are included in the NHFR. HAs account for approximately $34 \%$ of the total number of registered operations. More than $90 \%$ of the displaced femoral neck fractures in patients older than 70 years are treated with an HA, so the included operations make up the vast majority of the surgeries for these fractures. We did not include hip fractures treated with any form of osteosynthesis, as the recommendations in the guidelines are prophylaxis during surgery, and not after as is the case with HAs. Most HAs are performed by junior registrars, whereas total hip arthroplasties are performed by consultants specialising in hip surgery. We, therefore, excluded hip fractures treated with total hip arthroplasty to remove bias from more experienced surgeons.

We analysed 6 university hospitals and 44 non-university hospitals in Norway reporting to the NHFR. When

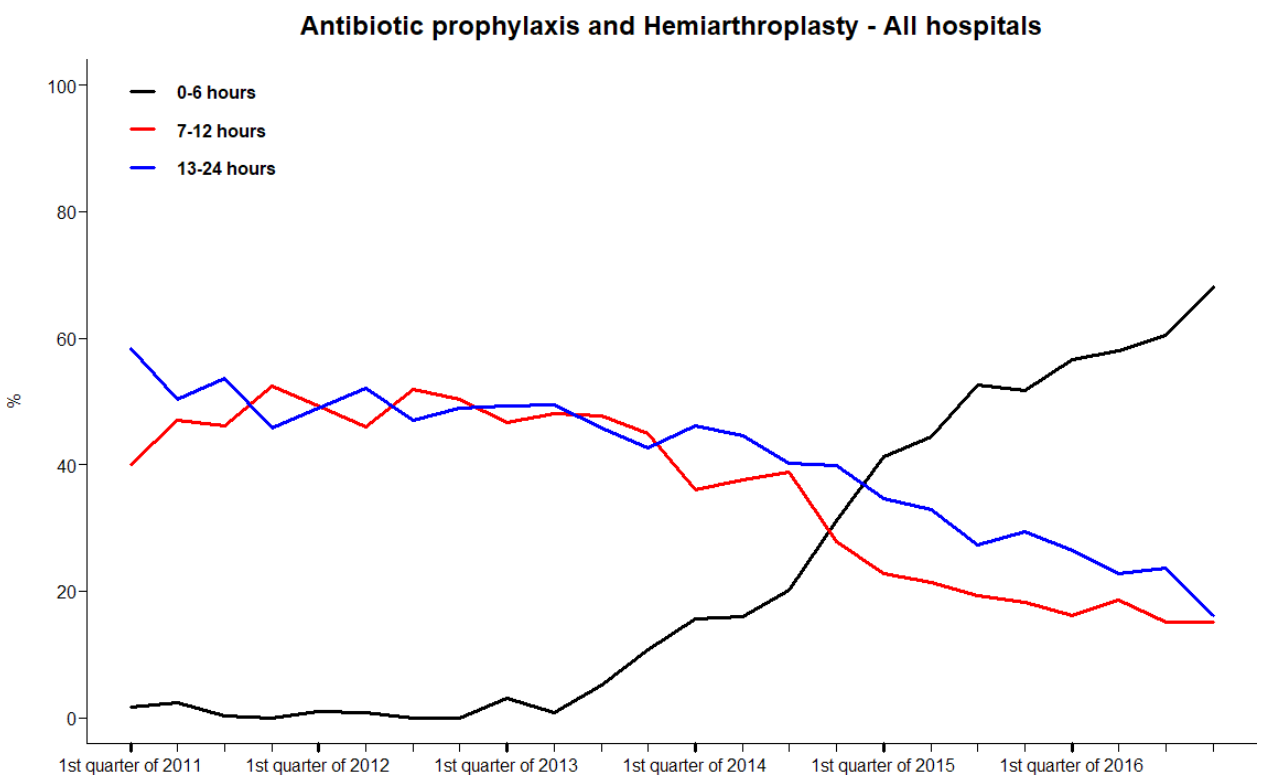

Figure 1 Antibiotic prophylaxis and hemiarthroplasty-all hospitals. 


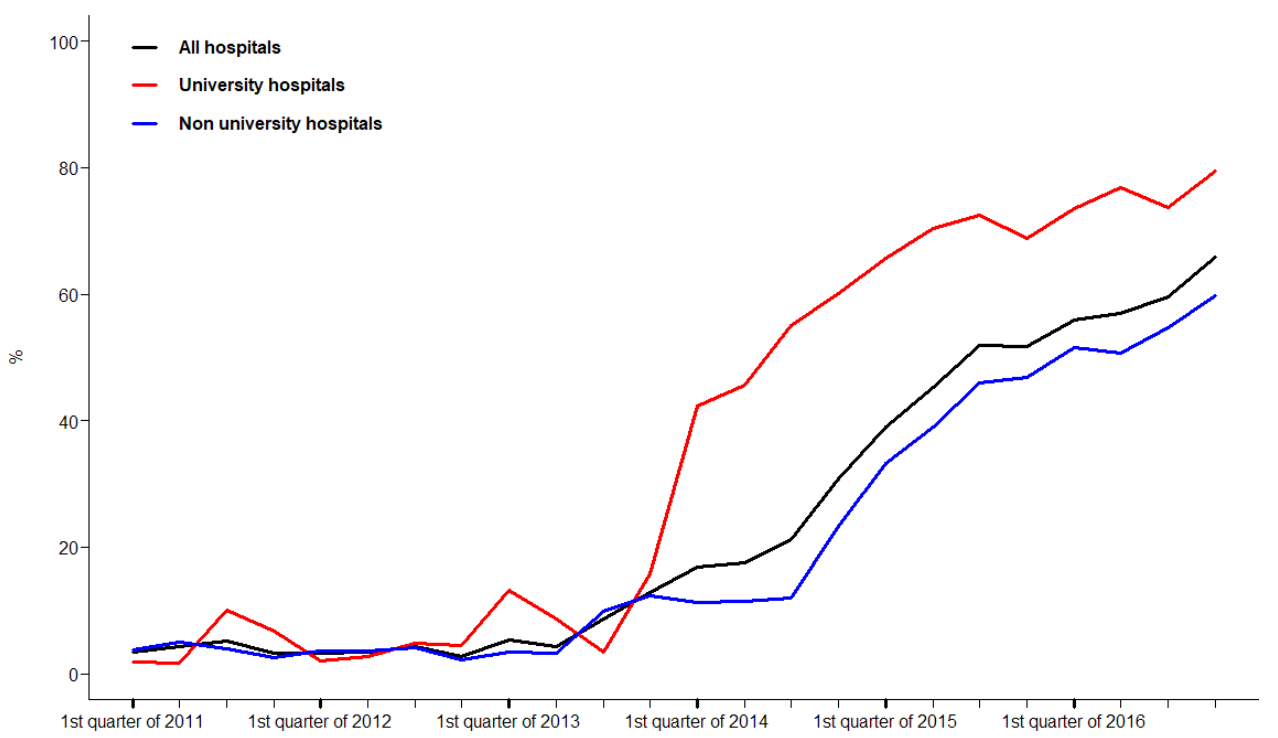

Figure 2 Indicator if new guidelines for antibiotics are followed-all hospitals.

cephalotin or clindamycin was used, we recorded whether it was administered correctly, and if there were any changes in their use from 2011 to 2016. We also assessed compliance, defined as $100 \%$ correct administration as described in the guidelines.

\section{Descriptive statistics}

The quarterly compliance with the national guidelines during 2011-2016 was calculated both for university hospitals and non-university hospitals. One university hospital submitted a high number of incomplete forms to the NHFR during the whole study period, and was consequently excluded from the comparisons of university hospitals. Analyses were performed using IBM SPSS, V.24.0 (IBM Corp.) and the statistical package R V.3.4.0 (http://www.R-project.org).

\section{Patients and public involvement}

This research was conducted without patient involvement. Patients were not invited to comment on the study design and were not consulted to develop patient relevant outcomes or interpret the results. Patients were not invited to contribute to the writing or editing of this document for readability or accuracy.

The NHFR has permission from the Norwegian Data Protection Authority to collect and store data on hip fracture treatment (permission granted on 3 January 2005: reference number 2004/1658-2 SVE/-). The patients have signed a written, informed consent, and in case they were not able to sign, their next of kin could sign the consent form on their behalf. This study only used data registered in the NHFR and no interventions were

Indicator if new guidelines for antibiotics are followed

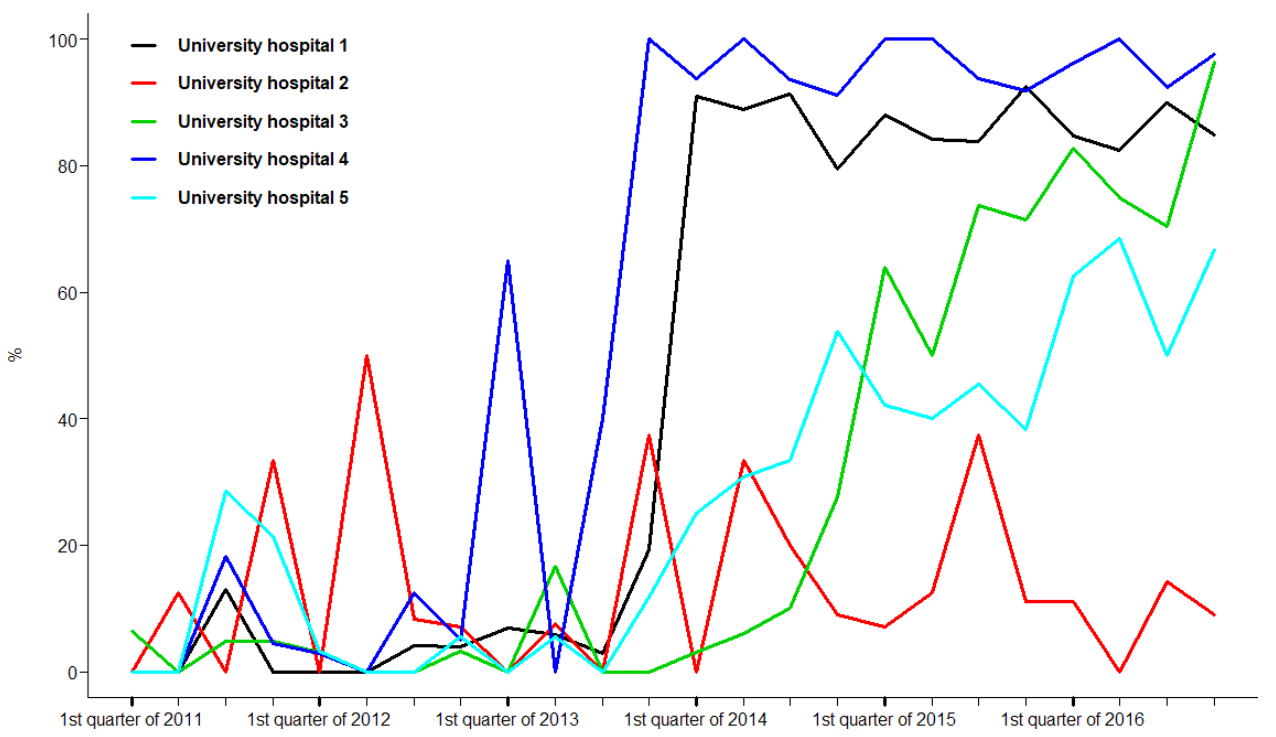

Figure 3 Indicator if new guidelines for antibiotics are followed-university hospitals. 
done. The study was, therefore, performed in accordance with the regulations from the Norwegian Data Protection Authority and no ethics approval was necessary.

\section{RESULTS}

\section{Types of antibiotics used 2011-2016}

In 2011, 99.6\% ${ }^{11}$ of HAs received intravenous antibiotic prophylaxis, but cephalotin or clindamycin was used in only $86.2 \%$ of all HAs. This number rose steadily throughout the study period: in 2016, one of the two recommended drugs was administered in $99.2 \%$ of HAs. There was a small increase in the use of clindamycin during the period, whereas other antibiotics were gradually abandoned (table 1 ).

\section{Compliance with the national guidelines}

Table 2 shows baseline data for the 13329 HAs included in the compliance analyses, dividing antibiotic prophylaxis according to the guidelines and other regimens. The groups were similar in age, gender, American Society of Anesthesiologists (ASA) class and cognitive function. HAs performed with a posterior approach were more often performed with the correct prophylactic regime compared with other surgical approaches. $10.8 \%$ of HAs in the study period were performed using a posterior approach. In 2011, only $4 \%$ of the HAs were performed with antibiotic prophylaxis as later recommended in the guidelines of 2013. We found a small but marked change towards administration of all four doses of cephalotin within 6hours during 2014 (figure 1). However, for clindamycin, no such trend was found. Although better than cephalotin, erronous administration remained at $10 \%-15 \%$ for the whole study period. This meant that only $21.9 \%$ of HAs received antibiotic prophylaxis in concordance with the guidelines in 2014.

The proportion of patients receiving correct administration of cephalotin increased steadily after 2014 and towards the end of the study period. In 2016, almost $60 \%$ of all registered HAs were performed with prophylaxis as recommended in the guidelines (figure 2). There were major differences between hospitals. Some hospitals showed a rapid change of practice shortly after the guidelines had been published, whereas others had yet to comply with the guidelines by the end of 2016. Two of the five university hospitals changed their routines according to the guidelines during the first months after they were published, two gradually became compliant and one did not comply at all (figure 3 ). University hospitals adapted to the new guidelines faster than non-university hospitals. There was, however, a similar rise in correct administration in both hospital categories (figure 2).

\section{DISCUSSION}

The change towards correct administration of antibiotic prophylaxis in HAs for hip fracture was slow after introduction of the national guidelines. At the end of the study period, only three out of five HAs were performed with the correct drug administered in the correct manner. Most university hospitals adapted to the new guidelines faster than non-university hospital, but one university hospital did not comply with the guidelines at all.

From a quality control perspective, any contemplated changes to a process must be thoroughly evaluated to fully assess their impact. This is a part of Shewhart's fourpart cycle of Plan, Do, Study and Act, ${ }^{12}$ and an essential part in improving the quality of any process. When the new guidelines were published, it was after an extensive evaluation (Plan). The introduction was performed by distributing the new guidelines by email and with lectures held around the country and publication on the National Directorate of Health webpage $(D o)$. We now need to evaluate whether hospitals follow the new guidelines, and whether following the guidelines has any effect on infection rates (Study). If Norwegian hospitals do not follow the guidelines, we need to understand why, and if there are differences in antibiotic regimes that lead to differences in infection rates, we then need to act $(A c t)$.

Prophylactic antibiotics are known to have a major impact on infection risk. ${ }^{8}$ It is the single most important prophylactic measure against surgical site infections. ${ }^{13-16}$ We found a gradual increase in adherence to the Norwegian guidelines published in 2013. Recommendations on time between doses were slowly implemented, and at the end of the study period, still less than $60 \%$ of the HAs were performed with antibiotic prophylaxis according to the guidelines. University hospitals were faster at adapting the new guidelines than non-university hospitals.

Several studies have reported on adherence to guidelines with regards to surgical antibiotic prophylaxis, ${ }^{17-21}$ with varying results. A Dutch study ${ }^{22}$ showed that guidelines can be effective in improving the process of care, but that there are large differences in the impact of each guideline. When evaluating the influence of a guideline, the first and most important factor to examine is whether the guidelines actually are being followed. If guidelines are not being followed, we need to understand why. Grimshaw and Russell ${ }^{23}$ suggested a classification for probability of success when implementing new guidelines, where local education of clinicians was the most important factor. He also advocated rigorous evaluation of existing guidelines. Cabana $e a^{24}$ gave seven reasons for why clinicians do not follow practical guidelines. All these barriers can, in our opinion, be overcome by strong leadership and education of the health practitioners.

There is clear evidence that checklists may have a positive impact on results. ${ }^{25-28}$ A study from 2011 concluded that leaders are a key factor in the implementation and further utilisation of checklists. ${ }^{29}$ Another tool that is available is a statistical process control (SPC).$^{30}$ This has been used for monitoring processes in real time in the process industry for many years and is gradually becoming a part of research into quality of healthcare. 


\section{Type of drug}

Cephalotin is not the most potent antibiotic against postoperative infections. But, when considering antibiotic stewardship and common bacteria causing postoperative infections, it has been considered the best choice for antibiotic prophylaxis in HAs in Norway. A more broadspectrum antibiotic prophylaxis will probably yield fewer postoperative infections, but would at the same time be ecologically unwanted.

In our study population, cephalotin and clindamycin were already the two most commonly used prophylactic antibiotics in HA surgery before the guidelines were published. There was an increase in use of these antibiotics during the study period, reaching almost complete adherence in choice of drug with the guidelines. There may always be indications for using other antibiotics, such as concomitant medical conditions. We, therefore, conclude that, when it comes to the type of antibiotic, Norwegian orthopaedic surgeons are adherent to today's guidelines.

\section{Timing}

Correct timing of antibiotics, defined as the recorded time interval in hours between first and last doses, should ensure that the concentration of antibiotics in the tissue stays above MIC at all times. With the short half-life of cephalotin, this can only be achieved by short intervals between doses.

In our study, two out of five HAs were performed with cephalotin prophylaxis using intervals exceeding $90 \mathrm{~min}$, 4 years after the introduction of the guidelines. Given today's guidelines, and understanding of how prophylactic antibiotics work, deviance from them is unrecommendable. Less than $60 \%$ adherence to the national guidelines 4 years after the introduction of new guidelines may necessitate an intervention by local hospital leaders as well as the Norwegian Directorate of Health.

\section{Differences between hospitals}

University hospitals should be at the forefront of change, and up to date on current knowledge. It is problematic that one university hospital did not comply with the obligation of reporting to the quality register (NHFR). This ought to be corrected $(A c t)$. It is also noticeable that one of the six university hospitals did not comply with the guidelines. In our opinion, there is no excuse for such oversight, and it should be remedied. Again, local leaders need to be involved, if not the National Directorate of Health may have to intervene. In Norway, each hospital generally uses one surgical approach and one standard prophylaxis for HAs. It is rare, if not non-existent, to find one hospital using several different approaches or allowing the administration of different antibiotic prophylaxis on a surgeon-by-surgeon basis. This may explain the difference we found when comparing surgical approaches. One of the few hospitals using the posterior approach was almost $100 \%$ adherent to the guidelines, thus giving this difference.

\section{Strengths/weaknesses}

The high number of procedures included and that nationwide results are presented are both strengths in the present study. When studying a large population using registerbased data, there are some inherent weaknesses. ${ }^{31}$ Most are connected to the questionnaire and the completeness of the registry. The coverage in the NHFR is $100 \%$ and the completeness is $94.5 \%$ for HAs. ${ }^{10}$ This high completeness in the NHFR yields a low selection bias and a high external validity of our results. Our data are limited by the questions and registrations on the operation form filled in by the surgeons. There is a possibility that the antibiotic prophylaxis actually given may be different from what the surgeon records. For example, Stefánsdóttir et $a \vec{l}^{32}$ showed in 2009 that although recommendations for timing of the preoperative antibiotic infusion were known, only $51 \%$ of the patients received it correctly. However, we have no reason to expect a systematically incorrect reporting from the surgeons. The timing of the first dose of antibiotic prophylaxis is not reported to the NHFR. This information would have strengthened our study on adherence to the national guidelines, but would have been even more important in a study investigating the benefit of correct antibiotic. The lack of clear guidelines for clindamycin when the guidelines were published is problematic when interpreting the results. However, we argue that allowing for the use of either two sets of guidelines available in the period removes some of the problem. That being said, we recognise this as problematic.

A high number of cases were excluded due to incomplete information on the operation forms. The excluded cases demonstrated similar baseline characteristics as the included patients (for all variables presented in table 2). They were excluded during the whole period we investigated (between 13\% and 18\% each year). Furthermore, except for one hospital, the excluded cases had been reported fairly evenly from all hospitals. A more complete registration would have increased the number of cases investigated, and accordingly strengthened our results. We do not know for sure whether the excluded cases represent a systematic reporting of incomplete data, or represent a random selection of cases which probably have had antibiotic prophylaxis according to the hospital's routine at the time of operation. However, we do know that this incomplete reporting comes from most of the reporting hospitals during the whole period investigated. There is, therefore, a reason to believe that most excluded patients had received either correct or wrong antibiotic prophylaxis. We, therefore, believe that the included cases make up a representative selection and can still be used to investigate compliance with guidelines at Norwegian hospitals, but we also acknowledge that the missing cases represent a weakness of our study.

\section{CONCLUSION}

The national guidelines have gradually become implemented at Norwegian hospitals. A rapid increase in 
correct use of antibiotic immediately after the introduction of the guidelines was only found in a few hospitals. Throughout the country, hospitals still fail to comply with the guidelines. This must be addressed, both when evaluating existing guidelines as well as when planning new guidelines. As long as guidelines are based in evidence, there are few, if any, reasons not to follow them.

By using checklists and combining them with the SPC data, it should be possible to follow processes and intervene when they are not stable. No single hospital in our study showed $100 \%$ adherence to the guidelines. This shows that there still exist individual surgeons not adherent to hospital policy and the national guidelines. Early identification of non-compliance needs be brought to the attention of local leaders. If this does not lead to change, the National Directorate of Health and the public should be notified.

Modern medicine is complex and dependent on compliance to evidence-based guidelines. Eminencebased medicine may still be warranted in some areas, but in fields where there are evidence-based guidelines it has no place. To conclude, we advocate more guidelines in complex and well-studied fields in medicine and strong adherence to existing ones.

\section{Author affiliations}

${ }^{1}$ Orthopaedic Department, Baerum Hospital, Vestre Viken Hospital Trust, Gjettum, Norway

${ }^{2}$ Institute of Clinical Medicine, University of Oslo, Oslo, Norway

${ }^{3}$ Norwegian Hip Fracture Register, Department of Orthopaedic Surgery, Haukeland University Hospital, Bergen, Norway

${ }^{4}$ Department of Orthopaedic Surgery, Haukeland University Hospital, Bergen, Norway

${ }^{5}$ Department of Clinical Medicine, University of Bergen, Bergen, Norway

${ }^{6}$ Norwegian Arthroplasty Register, Department of Orthopaedic Surgery, Haukeland University Hospital, Bergen, Norway

${ }^{7}$ Division of Orthopaedic Surgery, Oslo University Hospital, Oslo, Norway

Acknowledgements We would like to acknowledge the Norwegian Hip Fracture Register for help with both collection of data and statistical analysis.

Contributors TL and WF had the idea for the study. All authors contributed to the study design, writing, revising and improving the manuscript, data interpretation and provided a critical review of the manuscript. TL, J-EG and ED carried out data collection, data analysis and data interpretation. ED created all graphs.

Funding The authors have not declared a specific grant for this research from any funding agency in the public, commercial or not-for-profit sectors.

Competing interests None declared.

Patient and public involvement Patients and/or the public were not involved in the design, or conduct, or reporting, or dissemination plans of this research.

Patient consent for publication Not required.

Provenance and peer review Not commissioned; externally peer reviewed.

Data availability statement Data are available upon reasonable request. The data that support the findings of this study are available from the corresponding author, [TL], upon reasonable request.

Open access This is an open access article distributed in accordance with the Creative Commons Attribution Non Commercial (CC BY-NC 4.0) license, which permits others to distribute, remix, adapt, build upon this work non-commercially, and license their derivative works on different terms, provided the original work is properly cited, appropriate credit is given, any changes made indicated, and the use is non-commercial. See: http://creativecommons.org/licenses/by-nc/4.0/.
ORCID iD

Tom Lian http://orcid.org/0000-0003-0087-5598

\section{REFERENCES}

1 Engesaeter LB, Lie SA, Espehaug B, et al. Antibiotic prophylaxis in total hip arthroplasty: effects of antibiotic prophylaxis systemically and in bone cement on the revision rate of 22,170 primary hip replacements followed 0-14 years in the Norwegian arthroplasty register. Acta Orthop Scand 2003;74:644-51.

2 Helsedirektoratet. Nasjonale faglige retningslinje for bruk AV antibiotika I sykehus, 2013. Available: https://www.helsedirektoratet. no/retningslinjer/antibiotika-i-sykehus/antibiotikaprofylakse-vedkirurgi/ortopedisk-kirurgi

3 Atkins D, Best D, Briss PA, et al. Grading quality of evidence and strength of recommendations. BMJ 2004;328:1490.

4 Schurman DJ, Hirshman HP, Burton DS. Cephalothin and cefamandole penetration into bone, synovial fluid, and wound drainage fluid. J Bone Joint Surg Am 1980;62:981-5.

5 Johnson DP. Antibiotic prophylaxis with cefuroxime in arthroplasty of the knee. J Bone Joint Surg Br 1987;69:787-9.

6 Classen DC, Evans RS, Pestotnik SL, et al. The timing of prophylactic administration of antibiotics and the risk of surgical-wound infection. N Engl J Med 1992;326:281-6.

7 Bratzler DW, Houck PM. Antimicrobial prophylaxis for surgery: an Advisory statement from the National surgical infection prevention project. Am J Surg 2005;189:395-404.

8 Boxma H, Broekhuizen T, Patka P, et al. Randomised controlled trial of single-dose antibiotic prophylaxis in surgical treatment of closed fractures: the Dutch trauma trial. Lancet 1996;347:1133-7.

9 Gjertsen J-E, Engesaeter LB, Furnes O, et al. The Norwegian hip fracture register: experiences after the first 2 years and 15,576 reported operations. Acta Orthop 2008;79:583-93.

10 Furnes O, Gjertsen J-E, Hallan G, et al. Norwegian National Advisory unit on arthroplasty and hip fractures. Norwegian arthroplasty register, Norwegian cruciate ligament register, Nor-wegian hip and fracture register, Norwegian paediatric hip register, 2019. Available: http://nrlweb.ihelse.net/eng/Rapporter/Report2019_english.pdf

11 Engsaeter LB, Havelin LI, et al. Annual report. Norwegian arthroplasty register 2012 2012:134-5.

12 Shewhart WA, Deming WE. Statistical method from the viewpoint of quality control. Washington: The Graduate school, the Department of agriculture, 1939.

13 Fogelberg EV, Zitzmann EK, Stinchfield FE. Prophylactic penicillin in orthopaedic surgery. J Bone Joint Surg Am 1970;52:95-8.

14 Pavel A, Smith RL, Ballard A, et al. Prophylactic antibiotics in clean orthopaedic surgery. J Bone Joint Surg Am 1974;56:777-82.

15 Henley MB, Jones RE, Wyatt RW, et al. Prophylaxis with cefamandole nafate in elective orthopedic surgery. Clin Orthop Relat Res 1986;209:249???254-54.

16 Gillespie WJ, Walenkamp GH. Antibiotic prophylaxis for surgery for proximal femoral and other closed long bone fractures. Cochrane Database Syst Rev 2010;3:CD000244.

17 Wright JD, Hassan K, Ananth CV, et al. Use of guideline-based antibiotic prophylaxis in women undergoing gynecologic surgery. Obstet Gynecol 2013;122:1145-53.

18 Gouvêa M, Novaes CdeO, Pereira DMT, et al. Adherence to guidelines for surgical antibiotic prophylaxis: a review. Braz J Infect Dis 2015;19:517-24.

19 Bull AL, Russo PL, Friedman ND, et al. Compliance with surgical antibiotic prophylaxis--reporting from a statewide surveillance programme in Victoria, Australia. $J$ Hosp Infect 2006;63:140-7.

20 Schmitt C, Lacerda RA, Turrini RNT, et al. Improving compliance with surgical antibiotic prophylaxis guidelines: a multicenter evaluation. Am J Infect Control 2017;45:1111-5.

21 van Kasteren MEE, Kullberg BJ, de Boer AS, et al. Adherence to local Hospital guidelines for surgical antimicrobial prophylaxis: a multicentre audit in Dutch hospitals. J Antimicrob Chemother 2003;51:1389-96.

22 Lugtenberg M, Burgers JS, Westert GP. Effects of evidence-based clinical practice guidelines on quality of care: a systematic review. Qual Saf Health Care 2009;18:385-92.

23 Grimshaw JM, Russell IT. Effect of clinical guidelines on medical practice: a systematic review of rigorous evaluations. Lancet 1993;342:1317-22.

24 Cabana MD, Rand CS, Powe NR, et al. Why don't physicians follow clinical practice guidelines? A framework for improvement. JAMA 1999;282:1458-65. 
25 Pronovost P, Needham D, Berenholtz S, et al. An intervention to decrease catheter-related bloodstream infections in the ICU. N Engl J Med 2006;355:2725-32.

26 Weiser TG, Haynes AB, Dziekan G, et al. Effect of a 19-item surgical safety checklist during urgent operations in a global patient population. Ann Surg 2010;251:976-80.

27 Haynes AB, Weiser TG, Berry WR, et al. A surgical safety checklist to reduce morbidity and mortality in a global population. $N$ Engl $\mathrm{J}$ Med 2009;360:491-9.

28 Wæhle HV, Harthug S, Søfteland E, et al. Investigation of perioperative work processes in provision of antibiotic prophylaxis: a prospective descriptive qualitative study across surgical specialties in Norway. BMJ Open 2019;9:e029671.

29 Conley DM, Singer SJ, Edmondson L, et al. Effective surgical safety checklist implementation. J Am Coll Surg 2011;212:873-9.

30 Doty LA. Statistical process control. 2nd ed. New York: Industrial Press, 1996: 379.

31 Thygesen LC, Ersbøll AK. When the entire population is the sample: strengths and limitations in register-based epidemiology. Eur $J$ Epidemiol 2014;29:551-8.

32 Stefánsdóttir A, Robertsson O, W-Dahl A, et al. Inadequate timing of prophylactic antibiotics in orthopedic surgery. We can do better. Acta Orthop 2009;80:633-8. 